(c) American Dairy Science Association, 2004.

\title{
Genetic Analysis of Male and Female Fertility Using Longitudinal Binary Data
}

\author{
T. A. Averill, ${ }^{1}$ R. Rekaya, ${ }^{1}$ and K. Weigel ${ }^{2}$ \\ ${ }^{1}$ Department of Animal and Dairy Science, \\ The University of Georgia, Athens 30602 \\ ${ }^{2}$ Department of Dairy Science, \\ University of Wisconsin, Madison 53706
}

\begin{abstract}
A longitudinal Bayesian threshold analysis of insemination events during the first $250 \mathrm{~d}$ after calving of first-parity Holsteins was carried out. The outcome of an insemination event was treated as a binary response of either a success (1) or a failure (0). Thus, all breeding information for a cow, including all service sires, was included, thereby allowing for a joint evaluation of male and female fertility. An edited data set of 297,823 insemination records from 151,758 first lactation cows was used. On the liability scale, the model included the systematic effects of herd-year of insemination, technician, month of insemination, and regressions on age of service sire, 3 test days in the first $100 \mathrm{~d}$ of lactation (early milk yield), and days in milk at insemination. The random effects in the model were the additive breeding value, the permanent effect of the cow, and the service sire effect. Posterior mean (standard deviation) of the dispersion parameters in the model were $0.034(0.006)$, $0.009(0.001)$, and $0.171(0.013)$ for the additive, service sire, and permanent environmental variances, respectively. The residual variance was fixed at 1 , as a result of the nonidentifiability of the threshold model. The posterior mean (standard deviation) of heritability was $0.028(0.005)$. This point estimate of heritability is well within the range of available estimates for the trait. Thus, these estimates suggest that some genetic variation exists that can potentially be used to improve reproductive performance or at least avoid its further deterioration. The estimate of the regression coefficient on age of service sire was 0.001 , indicating better fertility among older bulls. However, this result has to be interpreted with caution given the preferential use of proven bulls on well-managed cows (as opposed to problem breeders). The estimate of the regression coefficient was negative (-0.005) for early milk yield, as expected, and positive $(0.003)$ for days in milk at insemination. This
\end{abstract}

Received January 14, 2004.

Accepted July 24, 2004.

Corresponding author: T. A. Averill; e-mail: taverill@uga.edu. suggests that high-producing cows are less likely to conceive at the beginning of lactation.

(Key words: male and female fertility, longitudinal binary data, dairy)

\section{INTRODUCTION}

The main goal of dairy producers is to maximize returns from milk production while minimizing costs (Freeze et al., 1992). This forces dairy producers to maintain reproductive performance while obtaining a high level of milk production. However, long-term selection for milk yield has caused deterioration in some nonproduction or "secondary" traits as a result of antagonistic genetic relationships. As a result, more cows are being culled involuntarily as a consequence of poor fertility (Hansen et al., 1983; Weller, 1989; Lopez-Gatius et al., 2002). This decline in fertility has become a major problem in the dairy industry, causing significant economic losses (Taylor et al., 1985; Clay et al., 2001; Olori et al., 2002) due to additional insemination costs, decreased milk production per day of herd life, and decreased intensity of selection (Hodel et al., 1995). Thus, improvement in, or at least the maintenance of, herd fertility has become a major objective in genetic improvement programs worldwide. The outcome of an insemination depends on both male and female fertility, and it has been well documented that several factors, such as herd management, heat detection practices, and genetics can improve reproductive performance. Although the heritabilty of fertility is low, ranging from 1 to $10 \%$ depending on the definition of the trait and the methodology used for its analysis, there is a consensus that sufficient genetic variability exists, and this can be exploited to improve reproductive performance.

Several types of traits are used in fertility evaluation, ranging from binary (discrete) responses to continuous or interval traits. Consequently, depending on the trait definition, different models and methodologies have been implemented to analyze reproductive performance. Raheja et al. (1989b) used a mixed linear model to study the relationships between bull fertility with 
daughter fertility and production traits in Holstein cattle; 3 fertility traits (days from calving to first breeding, days open, and number of AI services per conception) and 3 production traits (breed class average-milk, breed class average-fat, and breed class average-fat \%) in the first 2 lactations were used. Breed Class Average (BCA) is an index combining milk, fat, and protein used by all milk recording programs across Canada. It consists of comparing a cow's actual or projected $305 \mathrm{~d}$ production to the BCA standard for a cow of the same breed, age at calving, and month of calving. The estimated genetic correlations (based on the correlations of estimated breeding values) between female fertility, male fertility, and production traits ranged between -0.56 and 0.13. Weigel and Rekaya (2000) estimated genetic parameters associated with male and female fertility traits using linear and threshold models. Nonreturn rate and confirmed pregnancy after 60 and $90 \mathrm{~d}$ defined as binary traits were considered. The proportion of phenotypic variance explained by service bull effect ranged from 0.005 to 0.008 . In all cases, estimates based on a threshold model were higher. Heritability estimates for female fertility (i.e., the proportion of variance due to the animal being inseminated) ranged from 1.4 to $3.1 \%$. In a recent study, Brotherstone et al. (2002) investigated the relationships between 3 fertility traits (calving interval, number of inseminations, and conception rate to first insemination) and 9 production traits (daily milk, fat plus protein, or milk energy yield at the third test; daily milk, fat plus protein, or milk energy yield at the test nearest to the body condition score date; and 305-d lactation milk, fat plus protein, and milk energy yield). They concluded that heritabilities of fertility traits were very similar and ranged from 0.03 to 0.04 . However, the genetic correlations were antagonistic, ranging from -0.34 to 0.43 . The genetic correlation between calving interval and 305-d milk energy yield (0.43) suggests that an increase in 305-d milk yield is associated with an increase in calving interval.

Grosshans et al. (1996) used a sire model and restricted maximum likelihood methodology to analyze 11 fertility traits and 3 production traits (milk yield, fat yield, and protein yield) and concluded that the heritability of fertility traits ranged from 0.007 (number of services per conception) to 0.134 (age at calving). Genetic correlations between milk production and fertility traits, except age at first calving, were low $(-0.248$ to 0.289 ). However, the correlations of age at calving with production traits were higher and positive (antagonistic), being $0.209,0.447$, and 0.704 with milk yield, fat yield, and protein yield, respectively, indicating an increase in age at calving with an increase in milk production.
Kadamideen et al. (2000) estimated genetic parameters for various disease traits and conception after first insemination in UK dairy population using linear and threshold models. They concluded that the threshold model yields slightly higher estimates. In fact, the heritability of the fertility trait was 0.01 and 0.012 using linear and threshold models, respectively.

Most of the previous research on dairy cattle fertility has focused on separate analyses of female and male fertility. More importantly, not all sources of variation are accounted for in many analyses, particularly when only one record per cow is used. Weigel (2000) reported that almost $50 \%$ of the usable data is discarded by considering only first services, because at least half of the cows have repeated insemination data available. The same author concluded that the use of such information is desirable. Furthermore, a high proportion of the fertility data is usually discarded as a result of inconsistencies in data recording that necessitate stringent editing. Thus, including the repeated records will increase the amount of information, leading to more accurate sire evaluations. However, when using a single record per cow, there is no easy way to account appropriately for the service sire effect because only one service sire will be accounted for. In the majority of cases, cows need more than one insemination per conception, and it is inappropriate to account for one of the service bulls and ignore all others. Another issue of interest is the sequence of service sires for cows having more than one insemination. For 2 cows having the same number of inseminations to the same bulls (but in a different sequence), differences in sequence are not accounted for with most models, and this may bias the prediction of both male and female fertility. An alternative method consists of modeling the number of inseminations per cow as repeated binary responses, thereby allowing the use of all available information and accounting properly for all factors affecting male and female fertility.

The objective of this study was to develop and implement a longitudinal binary model for the genetic evaluation of male and female fertility while making use of all available information.

\section{MATERIALS AND METHODS}

The data consisted of insemination records from dairy herds in California, generated between 2002 and 2003 and provided by AgriTech Analytics. The trait of interest was the outcome of all insemination events $(1=$ success, $0=$ failure). Thus, if a cow conceived after 3 inseminations, her response vector was $(0,0,1)$. If a cow conceived after one insemination, her response vector was (1). Only first parity cows were included in the analysis of 297,823 records. Data editing consisted of 
Table 1. A descriptive summary of the edited data.

\begin{tabular}{lcccc}
\hline & & \multicolumn{3}{c}{ Inseminations } \\
\cline { 3 - 5 } & Number & 1st & 2nd & $3+{ }^{1}$ \\
\hline Cows & 151,758 & & & \\
Records & 297,823 & & & \\
Successful & 128,889 & 73,207 & 34,966 & 20,716 \\
Failed & 168,934 & 78,551 & 43,585 & 46,798 \\
& & & Mean & SD \\
Service sires & 3190 & & 93.36 & 229.75 \\
Technicians & 2179 & & 136.68 & 279.63 \\
\hline
\end{tabular}

${ }^{1}$ Third and subsequent inseminations.

keeping only pregnant cows (those with a successful insemination as verified by a veterinary pregnancy examination) and nonpregnant cows that had at least 3 insemination events within an opportunity period of $250 \mathrm{~d}$ after calving. Further, cows with inconsistent identification, more than one successful insemination per lactation, or an unrealistic interval between consecutive inseminations were removed. After editing, the data consisted of a total of 151,758 cows with 297,823 records, averaging 1.96 inseminations per cow. The data also included a total of 2179 technicians, $3190 \mathrm{AI}$ service sires, and 990 herd-year contemporary groups. The averages for number of inseminations per technician and service sire were 137 and 93, respectively. A more detailed summary of the data is presented in Table 1.

The pedigrees of these cows had a high proportion of missing or unknown sires, due to a high percentage of cows in California having missing sire identification. After matching the identification numbers in the data and pedigree files provided by AgriTech Analytics with the sire pedigrees from the National Association Animal Breeders, the international sire identification numbers were determined and used in building the pedigree. In general, the pedigree file was of poor quality and consisted of 159,250 animals.

\section{Statistical Model and Implementation}

The basic latent variable model for the analysis of cross-sectional binary responses in an animal breeding context has been available for more than 20 years (Gianola, 1982). The longitudinal threshold model, as presented by Gianola and Rekaya (2000) and Heringstad et al. (2001), is an extension of the cross-sectional model. As with the basic threshold model, it consists of postulating the existence of an unobserved continuous random variable that relates to the observed binary or discrete response.

Let $\mathbf{y}_{\mathrm{i}}=\left(\mathrm{y}_{\mathrm{it}_{1}}, \mathrm{y}_{\mathrm{it}_{2}, \ldots}, \mathrm{y}_{\mathrm{it}}\right)_{\mathrm{i}}{ }^{\prime}$ be a $\mathrm{n}_{\mathrm{i}} \times 1$ vector of binary responses for an animal, $(i=1,2, \ldots, q)$ observed at times $t_{1}, t_{2}, \ldots, t_{n_{i}}$. As in the cross-sectional analysis, the binary response observed at a time $t_{j}$ related to an underlying random variable satisfying:

$$
y_{i j}=\left\{\begin{array}{l}
1 \text { if } l_{i j}>T \\
0 \text { otherwise }
\end{array}\right.
$$

where the subscript $j$ represents time $t_{j}$ and will be used as such from here on, and $\mathrm{T}$ is a threshold value. Further, it is assumed that

$$
l_{i j} \sim N\left(\mu_{i j}, \sigma_{e}^{2}\right)
$$

The probability of observing a positive case (success) is:

$$
\begin{aligned}
p_{i j} & =\operatorname{pr}\left(l_{i j}>T \mid \mu_{i j}\right) \\
& =1-\operatorname{pr}\left(l_{i j}<T \mid \mu_{i j}\right) \\
& =1-\Phi\left(\frac{T-\mu_{i j}}{\sigma_{e}}\right)
\end{aligned}
$$

where $\Phi$ is the cumulative distribution function of standard normal. It is clear from [2] that it is not possible to infer $\mu_{i j}, T$ and $\sigma_{e}^{2}$ separately. Hence, some restrictions are placed on 2 of the 3 model parameters. A common choice is to set $\mathrm{T}=0$ and $\sigma_{e}^{2}=1$, leading to:

$$
p_{i j}=\operatorname{pr}\left(l_{i j}>T \mid \mu_{i j}\right)=1-\Phi\left(-\mu_{i j}\right)=\Phi\left(\mu_{i j}\right)
$$

where $\mu_{i j}$ can be linearly related to a set of systematic and random effects.

Furthermore, a mixed linear model can be used to express the relationship between liability and $\mu_{i j}$. In matrix notation, the model can be written as:

$$
\mathbf{l}=\mathbf{X} \boldsymbol{\beta}+\mathbf{Z u}+\mathbf{W}_{1} \mathbf{p}+\mathbf{W}_{2} \mathbf{s}+\mathbf{e}
$$

where $\mathbf{l}$ is a vector of unobserved liabilities; $\beta$ is the vector of systematic effects (herd-year of insemination, technician, month of insemination and regression coefficients on age of service sire (months), early milk yield (mean of test day records within the first $100 \mathrm{~d}$ of lactation), and DIM to insemination); $\mathbf{u}$ is vector of additive breeding values; $\mathbf{p}$ is vector of permanent environmental effects; $\mathbf{s}$ is vector of service sires; $\mathbf{e}$ is the vector of residual terms; and $\mathbf{X}, \mathbf{Z}, \mathbf{W}_{\mathbf{1}}, \mathbf{W}_{\mathbf{2}}$ are known incidence matrices with the appropriate dimensions.

The reason for using herd-year instead of herd-yearmonth as contemporary group was the small number of records in the latter and, consequently, the large number of classes containing all successes or all failures. 
Based on the assumptions made earlier, the conditional distribution of liabilities given the model parameters was:

$$
\mathrm{p}(\mathbf{l} \mid \boldsymbol{\beta}, \mathbf{u}, \mathbf{p}, \mathbf{s}) \sim \mathrm{N}\left(\mathbf{X} \boldsymbol{\beta}+\mathbf{Z u}+\mathbf{W}_{1} \mathbf{p}+\mathbf{W}_{2} \mathbf{s}, \mathbf{I}\right)
$$

For a full Bayesian implementation of [4], prior distributions for the model parameters are required. To avoid a potentially improper posterior distribution, the following priors were assumed:

A normal distribution with mean 0 and a large variance was assumed as a prior for the systematic effects, $\beta$ :

$$
p\left(\beta_{i}\right) \sim N\left(0,10^{4}\right)
$$

Multivariate normal distributions were assumed for all random effects in the model:

$$
\begin{gathered}
p\left(\mathbf{u} \mid \sigma_{u}^{2}\right) \sim N\left(\mathbf{0}, \mathbf{A} \sigma_{u}^{2}\right) \\
p\left(\mathbf{p} \mid \sigma_{p}^{2}\right) \sim N\left(\mathbf{0}, \mathbf{I} \sigma_{u}^{2}\right) \\
p\left(\mathbf{s} \mid \sigma_{s}^{2}\right) \sim N\left(\mathbf{0}, \mathbf{I} \sigma_{s}^{2}\right)
\end{gathered}
$$

where $\sigma_{u}^{2}, \sigma_{p}^{2}$, and $\sigma_{s}^{2}$ were the additive, permanent environmental, and service sire variances, respectively.

For the 3 variances, a flat bounded prior was assumed:

$$
p\left(\sigma_{k}^{2}\right) \sim U[0,1]
$$

where $\mathrm{U}(\cdot)$ is the uniform distribution and $k=\{u, p, s\}$.

The augmented joint posterior distribution is obtained as the product of densities in [4]-[6], and all conditional posterior distributions follow easily. Albert and Chib (1993) and Sorensen et al. (1995) give all needed conditional distributions. The fully conditional posterior distributions of $\beta, \mathbf{u}, \mathbf{p}, \mathbf{s}, l, \sigma_{u}^{2}, \sigma_{s}^{2}$, and $\sigma_{p}^{2}$ are all in closed form, being normal for $\beta, \mathbf{u}, \mathbf{p}, \mathbf{s}$, truncated normal for each $l_{i}$, and scaled inverted $\chi^{2}$ for $\sigma_{u}^{2}, \sigma_{s}^{2}$, and $\sigma_{p}^{2}$. A detailed derivation of these conditional distributions can be found in Heringstad et al. (2001) and Rekaya et al. (2000).

Convergence diagnostics were assessed using the method of Raftery and Lewis (1992) and visual inspection of parameter trace plots. The required length of the burn-in period was less than 6,000 iterations for all parameters. Thus, a total single chain length of 100,000 iterations of the Gibbs sampler was used, with a conservative burn-in period of 25,000 iterations. The remaining 75,000 iterations were retained without thinning for postGibbs analysis.
Table 2. Summary of the posterior distributions of the variance components and heritability.

\begin{tabular}{lllll}
\hline Parameter $^{1}$ & Mean & SD & \multicolumn{2}{c}{ HPD $(95 \%)^{2}$} \\
\hline$\sigma_{\mathrm{a}}^{2}$ & 0.034 & 0.006 & 0.023 & 0.045 \\
$\sigma_{\mathrm{s}}^{2}$ & 0.009 & 0.001 & 0.007 & 0.011 \\
$\sigma_{\mathrm{p}}^{2}$ & 0.171 & 0.013 & 0.145 & 0.198 \\
$\mathrm{~h}^{2}$ & 0.028 & 0.005 & 0.019 & 0.037 \\
\hline
\end{tabular}

${ }^{1} \sigma_{\mathrm{a}}^{2}=$ Additive genetic variance, $\sigma_{\mathrm{s}}^{2}=$ service sire variance, $\sigma_{\mathrm{p}}^{2}=$ permanent environmental variance, and $\mathrm{h}^{2}=\sigma_{\mathrm{a}}^{2} /\left(\sigma_{\mathrm{a}}^{2}+\sigma_{\mathrm{s}}^{2}+\sigma_{\mathrm{p}}^{2}+1\right)$.

${ }^{2} \mathrm{HPD}(95 \%)=$ Lower and upper bounds of highest probability density interval.

\section{RESULTS AND DISCUSSION}

A summary of the posterior distributions of the variance components and heritability of insemination success is presented in Table 2 . The posterior mean (SD) of the additive variance was 0.034 (0.006). Although small, the posterior mean of the genetic variance indicates the presence of some genetic variability between cows that can be used to improve, or at least to avoid further deterioration of, the reproductive performance of Holstein cows. Weigel and Rekaya (2000), in a study of nonreturn rate at 60 and $90 \mathrm{~d}$ after insemination, used a threshold model and obtained similar estimates.

The posterior mean (SD) of the service sire variance was 0.009 (0.001). This point estimate tends to be slightly higher than those reported in the majority of fertility studies (Taylor et al., 1985; Hodel et al., 1995). A.-Ranberg et al. (2003), using a multiple-trait mixed linear model for 56-d nonreturn rate in heifers, reported estimates for service sire variance close to zero (lower than 0.0005). Although their estimates are not directly comparable with those obtained in this study, it seems that a higher service sire variance is obtained when repeat services, as well as the order in which they occur, are considered in the model. This is in part because service bulls have different potentials of impregnating cows as indicated by the service bull variance. Furthermore, the order in which bulls were used can lead to different outcomes of insemination events and subsequently to the variation in the data. Hansen et al. (1983) concluded that service sire variance was less than $1 \%$ for most of the fertility traits considered in their study. These estimates indicate some differences between service sires in their ability to impregnate cows. Furthermore, given the binary nature of a large number of fertility traits, a small difference in service sire fertility could be the reason for a successful (or failed) insemination event.

The posterior mean of the permanent environmental variance was $0.171(0.013)$. To the best of our knowledge, no previous longitudinal study of insemination 
events has been conducted, so estimates of the permanent environmental variance cannot be compared with literature values. This point estimate is higher than the additive and service sire estimates in this study.

The posterior mean of the heritability was 0.028 (0.005). Although relatively low, this estimate is within the range of reported values for this parameter in fertility studies. The literature estimates ranged from 0.026 to 0.04 for fertility traits measured as number of services per conception (Bar-Anan et al., 1985; Raheja et al., 1989a). Together with the estimate of the genetic variance, it seems that selection for a successful outcome of an insemination event is possible.

The estimate of the regression coefficient on age of the service sire was 0.001 , indicating a higher fertility for older (proven) bulls. However, this result has to be interpreted with caution given the preferential use of older bulls. Thus, young bulls tend to be mated with less fertile cows due to lower semen prices. Furthermore, there is the potential of a nonlinear relationship between insemination success and age of the service sire that cannot be accommodated by a simple regression.

The posterior mean of the regression coefficient on early milk yield was -0.005 . Although expected (cows with higher milk production have a lower chance of a successful insemination), this estimate was contradictory to the results found by Weigel and Rekaya (2000), who concluded that milk yield had no effect on $60-d$ nonreturn rate. Dematawewa and Berger (1998) found positive correlations of 0.53 and 0.63 between milk yield and days open and number of services per conception, respectively. This antagonistic relationship between milk yield and fertility traits was not supported by Weller (1989), who reported no correlation between conception status and milk yield.

The estimate of the regression coefficient on DIM at insemination was 0.003 . This positive regression indicates that cows being bred shortly after calving are less likely to become pregnant. Weigel and Rekaya (2000) reported a similar result for the effect of milk yield on $60-d$ nonreturn rate. In addition, it is possible that the ability of a cow to get pregnant could vary over time. Thus a random regression model that contemplates a more complex relationship between DIM and insemination success is more appropriate.

\section{CONCLUSIONS}

The use of a longitudinal model allows for the inclusion of all breeding information within an opportunity period. It avoids the elimination of useful information and makes possible the joint analysis of male and female fertility. Furthermore, it accounts for all service sires, as well as the order in which they were used, leading to potentially more precise estimates. Estimates of genetic parameters indicate the possibility of genetic improvement of reproductive performance through selection. This study is being extended to handle incomplete or "censored" records, including breeding events of nonpregnant cows after $250 \mathrm{~d}$, using a random regression model. Such a model will also allow for better modeling of the effects of age of service sire and DIM on the insemination outcome. Furthermore, it will allow the derivation of new selection criteria other than the single breeding value, such as time to conception and number of inseminations to conception. Finally, although survival analysis can handle the kind of data used in this study, we believe that a longitudinal model is practically more appropriate, because it allows the use of an animal model and can be incorporated into a joint genetic evaluation with other traits in the selection index in a straightforward manner.

\section{ACKNOWLEDGMENTS}

We thank the National Association of Animal Breeders for the financial support and AgriTech Analytics for providing the data for this research.

\section{REFERENCES}

A-Ranberg, I. M., B. Heringstad, G. Klemetsdal, M. Svendsen, and T. Steine. 2003. Heifer fertility in Norwegian dairy cattle: Variance components and genetic change. J. Dairy Sci. 86:2706-2714.

Albert, J., and S. Chib. 1993. Bayesian analysis of binary and polychotomous response data. J. Am. Statist. Assoc. 88:669-679.

Bar-Anan, R., M. Ron, and G. R. Wiggans. 1985. Associations among milk yield, yield persistency, conception, and culling of Israeli Holstein dairy cattle. J. Dairy Sci. 68:382-386.

Brotherstone, S., G. Banos, and M. P. Coffey. 2002. Evaluation of yield traits for the development of a UK fertility index for dairy cattle. Pages 01-28 in 7th World Congress on Genetics Applied to Livestock Production. Montpellier, France.

Clay, J. S., and B. T. McDaniel. 2001. Computing mating bull fertility from DHI nonreturn data. J. Dairy Sci. 84:1238-1245.

Dematawewa, C. M. B., and P. J. Berger. 1998. Genetic and phenotypic parameters for 305-day yield, fertility, and survival in Holsteins. J. Dairy Sci. 81:2700-2709.

Freeze, B. S., and T. J. Richards. 1992. Lactation curve estimation for use in economic optimization models in the dairy industry. J. Dairy Sci. 75:2984-2989.

Gianola, D. 1982. Theory and analysis of threshold characters. J. Anim. Sci. 54:1079-1096.

Gianola, D., and R. Rekaya. 2000. Bayesian random regression models for longitudinal binary data with applications to dairy cattle breeding. Symposium on Selected Topics in Variance Components Analysis. University of Florida, Department of Statistics. Online. Available http://www.stat.ufl.edu/symposium/2000/vca/. Accessed September 9, 2004.

Grosshans, T., Z. Z. Xu, L. J. Burton, and D. L. Johnson. 1996. Genetic parameters for fertility traits in seasonal dairy cattle. Dairy Cattle Breeding in New Zealand. Proceedings of the New Zealand Society of Animal Production 56:38-41.

Hansen, L. B., A. E. Freeman, and P. J. Berger. 1983. Variances, repeatabilities, and age adjustments of yield and fertility in dairy cattle. J. Dairy Sci. 66:281-292. 
Heringstad, B. R., R. Rekaya, D. Gianola, G. Klemetsdal, and K. A. Weigel. 2001. Bayesian analysis of liability to clinical mastitis in Norwegian cattle with a threshold model: effects of data sampling method and model specification. J. Dairy Sci. 84:2337-2346.

Hodel, F., J. Moll, and N. Kuenzi. 1995. Analysis of fertility is Swiss Simmental cattle-Genetic and environmental effects on female fertility. Livest. Prod. Sci. 41:95-103.

Kadarmideen, H. N., R. Thompson, and G. Simm. 2000. Linear threshold model genetic parameters for disease, fertility and milk production in dairy cattle. Anim. Sci. 71:411-419.

Lopez-Gatius, F., P. Santolaria, J. Yaniz, J. Rutllant, and M. LopezBejar. 2002. Factors affecting pregnancy loss from gestation day 38 to 90 in lactating dairy cows from a single herd. Theriogenology 57:1251-1261.

Newton, A. M., and A. E. Raftery. 1994. Approximate Bayesian inference with the weighted likelihood bootstrap. J. R. Stat. Soc. B. 56:3-48.

Olori, V. E., T. H. E. Meuwissen, and R. F. Veerkamp. 2002. Calving interval and survival breeding values as measure of cow fertility in a pasture-based production system with seasonal calving. J. Dairy Sci. 85:689-696.

Raftery, A. E., and S. Lewis. 1992. How many iterations in the Gibbs sampler? Pages 736-773 in Bayesian Statistics 5. J. M. Bernando, J. O. Berger, A. P. Dawid, and A. F. M. Smith, ed. Oxford University Press, New York, NY.
Raheja, K. L., E. B. Burnside, and L. R. Schaeffer. 1989a. Heifer fertility and its relationship with cow fertility and production traits in Holstein dairy cattle. J. Dairy Sci. 72:2665-2669.

Raheja, K. L., K. Nadarajah, and E. B. Burnside. 1989b. Relationship of bull fertility with daughter fertility and production traits in Holstein dairy cattle. J. Dairy Sci. 72:2679-2682.

Rekaya, R., K. A. Weigel, D. Gianola, B. Heringstad, and G. Klemetsdal. 2000. Methods for attenuating bias of variance component estimates in threshold models when herds are small. J. Dairy Sci. 83(Suppl. 1):56-57. (Abstr.)

Sorensen, D. A., S. Andersen, D. Gianola, and I. Korsgaard. 1995. Bayesian inference in threshold using Gibbs sampling. Genet. Sel. Evol. 27:229-249.

Taylor, J. F., R. W. Everett, and B. Bean. 1985. Systematic environmental, direct, and service sire effects on conception rate in artificially inseminated Holstein cows. J. Dairy Sci. 68:3004-3022.

Weigel, K. A. 2000. Toward national fertility evaluations. Proc 18th Technical Conference on Artificial Insemination and Reproduction.

Weigel, K. A., and R. Rekaya. 2000. Genetic parameters for reproductive traits of Holstein cattle in California and Minnesota. J. Dairy Sci. 83:1072-1080.

Weller, J. I. 1989. Genetic analysis of fertility traits in Israeli dairy cattle. J. Dairy Sci. 72:2644-2650. 